\title{
Interventional prevention of paradoxical embolism as the gold standard: End of discussion?
}

\author{
Radomir Nykl, Jan Precek, Martin Sluka, Stepan Hudec, David Richter, Petr Heinc, Milos Taborsky
}

Paradoxical embolism is one of the predominant causes of cryptogenic stroke and interventional secondary prevention, i.e., closure of the patent foramen ovale (PFO), is a much discussed issue. This review aims to provide a complex perspective on this topic, aggregates and comments on the available data and current guidelines. Several large trials were performed, some of which proved the superiority of PFO closure over pharmacotherapy while others have not. Studies detecting significant superiority of intervention worked with disproportionately high representation of large shunts compared to the general population. Other controversies also remain, such as the lack of comparison of the effect of modern anticoagulant/antiplatelet treatment to PFO closure or the risk of developing unwanted side effects after intervention, and these are discussed in detail. PFO closure is a suitable method for secondary prevention of paradoxical embolism and, therefore, cryptogenic stroke. However, this is only true for carefully selected patient populations and such selection is of the utmost importance in deciding on interventional or conservative treatment.

Key words: paradoxical embolism, patent foramen ovale, interatrial septal aneurysm, catheterization PFO closure

Received: January 30, 2021; Revised: May 27, 2021; Accepted: June 3, 2021; Available online: June 14, 2021

https://doi.org/10.5507/bp.2021.036

(c) 2021 The Authors; https://creativecommons.org/licenses/by/4.0/

Department of Internal Medicine I - Cardiology, University Hospital Olomouc, Czech Republic

Corresponding author: Radomir Nykl, e-mail: radomir.nykl@gmail.com

\section{INTRODUCTION}

By far the most common source of arterial embolism is atrial fibrillation, followed by heart stroke, atherosclerotic affections of extracardial arteries, cardiomyopathies, heart valve disorders and, relatively rarely, myxoma. Paradoxical embolism (PE) is another potential source of such events. PE is a thrombus (or another material) causing the systemic embolism through a right-to-left shunt. It predominantly affects the central nervous system (i.e., causing ischemic stroke or transitory ischemic attack TIA) (ref. ${ }^{1-3}$ ); nevertheless, it can also affect other organs or even multiple organs at the same time. A clear clinical confirmation of the diagnosis (detection of a thrombus caught in the interarterial shunt during esophageal echocardiography, EEG, or during autopsy, see Fig. 1, 2) is very rare; diagnosis is most often established as possible or highly probable based on indirect evidence and certain conditions.

Paradoxical embolism is a problem requiring multidisciplinary attention and the approaches adopted by individual specializations often differ. From the perspective of secondary prevention of ischemic stroke or TIA, the closure of a patent foramen ovale (PFO) or atrial septum defect (ASD) through cardiac catheterization is, in a welldefined population, reasonable. It is an alternative to the surgical closure (nowadays no longer performed as a single-purpose surgery) and pharmacotherapy (antiplatelet or anticoagulant treatment). Lately, however, opinion has been voiced that the use of better examination algorithms (longer observation and more detailed examinations) in patients after ischemic stroke and/or TIA can reveal other (predominantly arrhythmia-associated) causes of such problems even in patients whose diagnosis would have only recently been PE (ref. ${ }^{4}$ ). Such opinions, obviously, put the importance of PFO closure in prevention of such events in doubt. In this review, we present and discuss the available data on the significance of the interventional solution in the secondary prevention of PE and, in effect, cryptogenic ischemic stroke.

\section{METHODOLOGY}

The research strategy was aimed at evaluating studies focused on paradoxical embolism. Scientific articles from the period 1990 to 2020 were searched using the PubMed and SCOPUS databases. Search terms included: paradoxical embolism, patent foramen ovale, closure of patent foramen ovale. Only English and Czech language papers were reviewed.

\section{RESULTS}

\section{PE diagnosis}

A confirmed PE diagnosis can be established only where a thrombus is detected in the interatrial septum (see above and Fig. 2). Such a thrombus may get there from the venous system or form in situ. Unless such confirmation is achieved, the diagnosis is considered (highly) probable after eliminating risk factors of atherothrombo- 


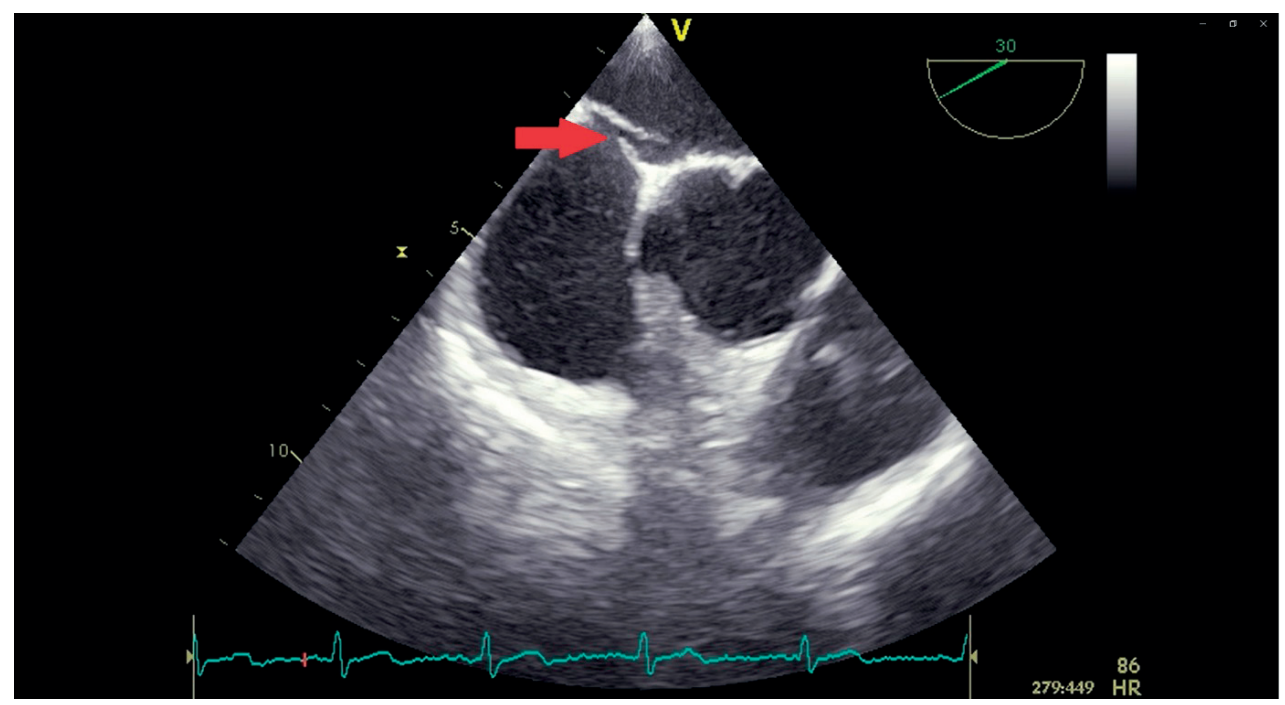

Fig. 1. Separation of the interatrial septum (indicated by red arrow).

sis (dyslipidemia, diabetes mellitus, arterial hypertension, smoking), atherosclerotic damage to the brain-supplying arteries, pro-coagulation disorders and possible immunological abnormalities (leading to vasculitis). It is especially important to search for a possible source of cardiac embolism, i.e., atrial fibrillation, presence of mechanical heart valve replacement, thrombus in the left atrium or ventricle, recent heart stroke, or, more rarely, infectious endocarditis or myxoma. At the same time, the diagnosis of PE is subject to meeting other conditions, the most important of which is the presence of a shunt between the venous and arterial systems. The other condition is the change of pressure gradients between the left and right atrium.

The most common form of the pulmonary and peripheral arterial systems is the patent foramen ovale (PFO, see Fig. 3). More rarely, atrial septum defect ASD or an extracardial pulmonary arteriovenous malformation can be cause of a shunt (Fig. 4) and, even more rarely, does this type of defect require any intervention. Both PFO and ASD are diagnosed using echocardiography (transesophageal echocardiography, TEE, potentially using a contrast agent or provoking maneuvers); in rare cases, additional examinations such as magnetic resonance imaging (MRI) or computed tomography (CT) can help in diagnosis. Extracardial shunts are best detected using CT or MRI.

\section{PFO and paradoxical embolism}

PFO, the most common cause of the arteriovenous shunt in $\mathrm{PE}$, is not considered a true defect of the atrial septum as no septal tissue is missing. PFO is a separation of the septum primum and secundum, which plays a crucial role in the fetal circulation. Normally, in about $70 \%$ of children, it closes within the first two months after birth (note, however, that the closure can be only functional, caused by a difference in the pressure in the left and right atrium); the closure can also occur later but after the first two months, the rate of closure declines. In total, vari-

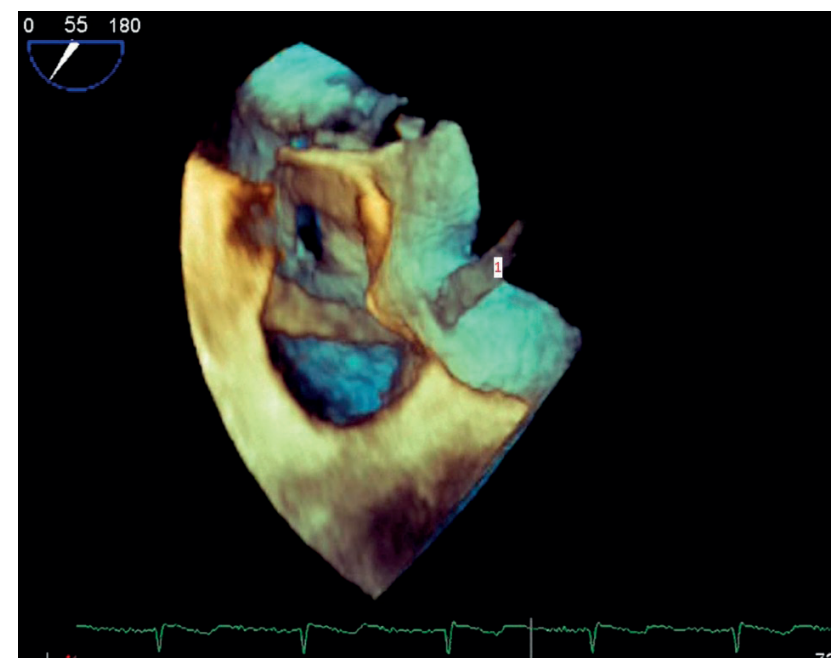

Fig. 2. 3D-ECHO image showing a thrombus captured in the interatrial septum (indicated by No 1).

ous authors report the overall incidence of PFO in adult population to be between 15 and $25 \%$ (ref. ${ }^{5,6}$ ).

PFO can remain clinically silent or cause hemodynamically insignificant left-to-right shunt flow. The shunt channel is usually between 3 and $22 \mathrm{~mm}$ long (ref. ${ }^{7,8}$ ). If, under certain conditions, a change in the interatrial pressure gradient occurs, even a small PFO that is normally clinically insignificant can cause a left-to-right shunt, thus laying down conditions for PE. The duration of such shunt is variable - it can be only short-term during cough or Valsalva maneuver, but it can also be long-term during pulmonary embolism or hypertension of various etiologies. Nevertheless, a PFO causing a hemodynamically significant left-to-right shunt requiring intervention is extremely rare.

In the literature, PFO is also reported to be a causation of the platypnea-orthodeoxia syndrome ${ }^{9,10}$ and in 


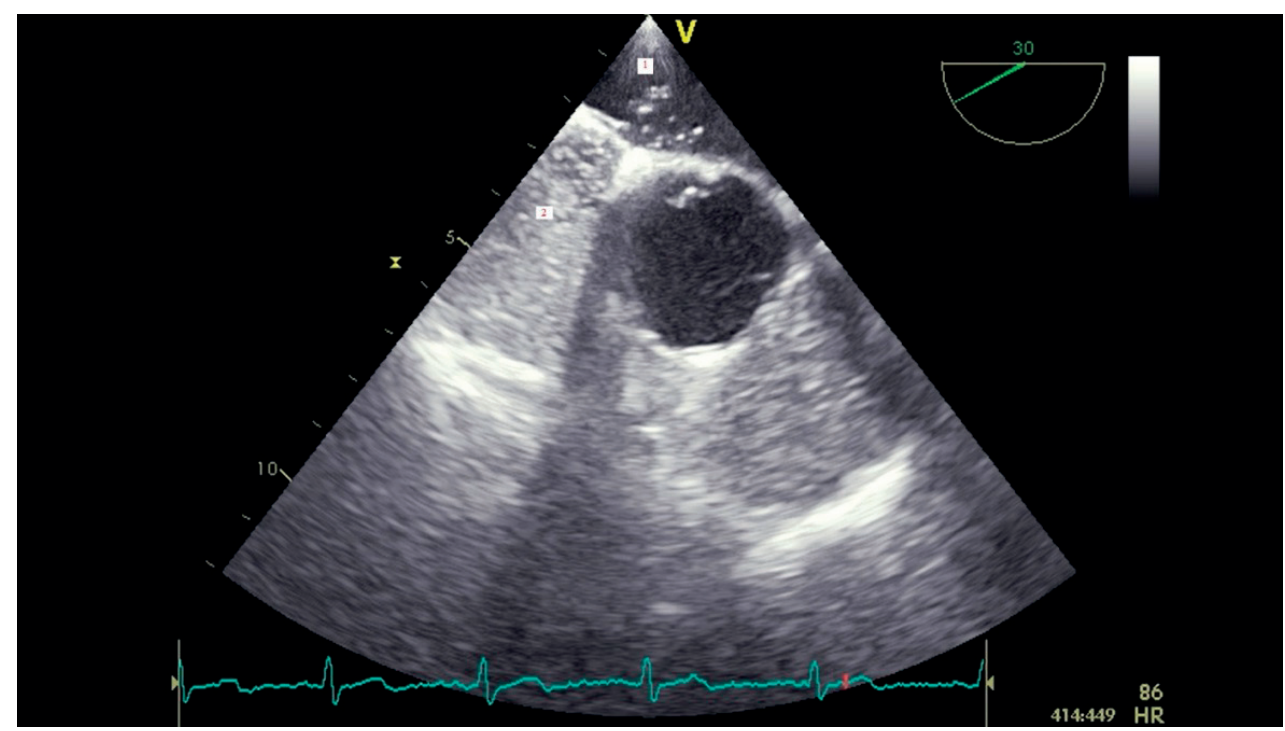

Fig. 3. Penetration of microbubbles of the contrast agent from the right to left atrium through PFO (bubbles in the left atrium indicated by No 1).

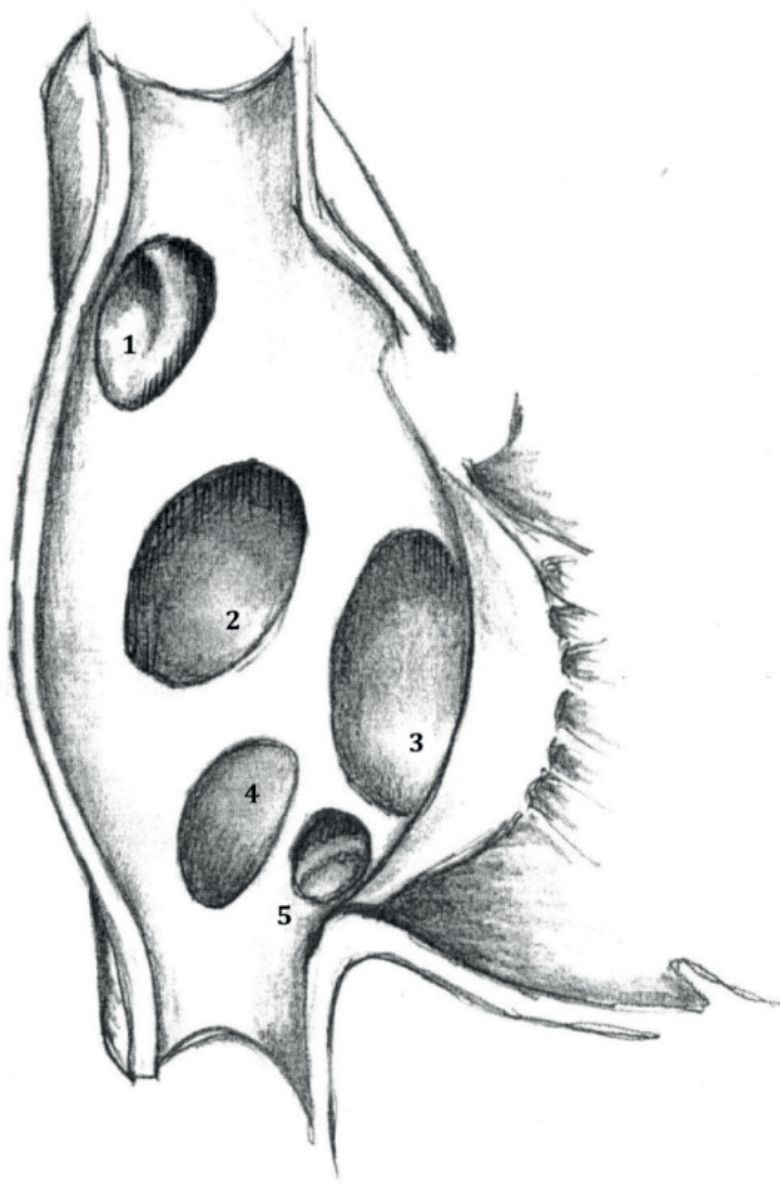

1. superior sinus venosus atrial septal defect (10\%) 2. secundum type atrial septal defect $(70 \%) 3$. primum secundum type atrial septal defect (15-18\%) 4. Inferior sinus venosus atrial septal defect (2-3\%) 5. Defect of the coronary sinus (rare).

Fig. 4. Schematic illustration of the interatrial defects and their share in the total number of atrial septal defects in percentage. migraines accompanied with aura. It is also discussed in association with altitude sickness and in divers. According to the EAPCI document ${ }^{10}$, PFO itself increases the risk of peripheral embolism in four ways: (i) paradoxic embolism, (ii) the thrombus can form in situ in the PFO channel, PFO also (iii) participates in the development of left atrial dysfunction and (iv) is a risk factor for development of supraventricular arrhythmias including atrial fibrillation and flutter. Other discussed issues include the morphological characteristics of PFO, i.e., the length of the channel, the presence and magnitude of the shunt flow at rest or during provocation, of septal aneurysm or hypermobility, or of other anatomical variants such as the Eustachean valve or Chiari network in the right atrium, the influence of which on the mechanism of PE or cryptogenic strokes is still under investigation.

\section{Traditional understanding of paradoxical embolism and its prevention}

Even nowadays, up to $25-30 \%$ of patients with ischemic stroke fall into the cryptogenic stoke category (i.e., stokes the reason for which has not been discovered). This number is much higher in younger persons - in patients with ischemic stroke at the age below 50, cryptogenic stroke is present in more than $50 \%$ of the patients ${ }^{4}$.

Of course, it is not possible to consider cryptogenic stroke and paradoxical embolism to be interchangeable. Nevertheless, many studies demonstrated a significantly higher representation of PFO in younger patients with otherwise unexplained reasons for stroke. Moreover, in such patients, the risk of recurrent strokes is increased $\left(\right.$ ref. $\left.^{11-13}\right)$.

In view of the aforementioned extremely difficult diagnosis of PE, the exact determination of the PE incidence and share in the development of stroke is not possible. It can be safely assumed that the absolute numbers of patients meeting the criteria of cryptogenic stroke (and, 
in effect, of PE) will keep dwindling. This is in particular due to the improving quality of the diagnostic methods and their better availability as well as to the new options in long-term patient monitoring. These facilitate the capture of structural and, in particular, functional deformities of the heart (predominantly atrial fibrillation) associated with a potential for cardioembolism. Thus, the number of patients who would have been diagnosed with a cryptogenic stroke decreases. On the other hand, it should also be noted that the incidence of atrial fibrillation grows with age and that the issue of PE (as the reason for cryptogenic stroke) predominantly concerns younger populations where the causal relationship between the presence of PFO and risk for stroke recurrence is more likely (ref. ${ }^{11,13-15}$ ).

\section{PFO closure as the prevention of stroke recurrence}

As mentioned above, one of the methods of secondary prevention (i.e., of PE recurrence) is the PFO closure through cardiac catheterization. This method is nowadays widely used despite critical opinions that studies focusing on this topic yielded inconsistent and contradictory results.

From the perspective of the principal indicator, i.e., reduction of stroke (and/or TIA) recurrence, the results in the group of patients with PFO closure has not unequivocally confirmed the superiority of this method compared to pharmacotherapy. The first major study CLOSURE I (ref. ${ }^{16}$ ) which from today's perspective can be perceived as obsolete because of the occluder type used, only relatively short follow-up period and recorded PFO characteristics and thus the results are usually not included in meta-analyses, provided no better results of PFO closure. Although the occurrences of ischemic stroke and TIA were lower in the intervention branch, the difference was not statistically significant. Similarly, significant superiority in the primary endpoints was not verified in the PC Trial study $^{17}$. In 2017, however, three randomized studies were published, namely RESPECT (ref. ${ }^{18}$ ) (499 patients with intervention), REDUCE (ref. ${ }^{19}$ ) (441) and CLOSE (ref. ${ }^{20}$ ) (248). These studies demonstrated a significant reduction in the ischemic stroke occurrence in the population with PFO closure (in the RESPECT study, this was only confirmed after the extension of the follow-up period). These were followed by a smaller study, DEFEND PFO (ref. ${ }^{21}$ ) (60 patients with intervention), in which no stroke occurrence was recorded in the intervention group (which is a result identical with that of the CLOSE study). The results are summarized in Table 1.

\section{Controversies related to the more recent studies}

Based on the newer studies, the use of PFO closure has grown more common; nevertheless, there are still calls for careful interpretation of such data and, in particular, for careful selection of patients who may benefit from PFO closure. Probably the most important issue associated with the newer studies is the disproportionally large representation of patients with large PFO (see Table 1) compared to older studies that have not demonstrated a significant effect of PFO closure - the distribution in those better corresponded with the general population. (ref. ${ }^{22-24}$ )

In addition, various authors defined the "large shunt" differently in their studies. The classification is typically based on the number of microbubbles of the contrast agent penetrating the PFO channel during the vagal maneuver detected by TEE. For example, the cut-off for large shunt was 20 bubbles in PC and RESPECT studies, 25 in the older CLOSURE 1 and REDUCE studies, and as much as 30 bubbles in the CLOSE study ${ }^{16-20}$.

Antiplatelet pharmacotherapy is a standard therapy in the case of PE (and, generally stroke); therefore, studies compare the PFO closure effectiveness predominantly with the antiplatelet therapy (or warfarin anticoagulation). However, results of new studies comparing the effectiveness of direct oral anticoagulants (DOAC) and aspirin for stroke prevention show that with the same risk of hemorrhagic complications, abixaban is more effective in preventing stroke ${ }^{25}$. None of the studies on the effectiveness of PFO closure, however, compared it directly to that of DOAC. Modern anticoagulation therapy thus can yield significantly better results than the pharmacotherapy administered in the aforementioned studies. Considering the risks associated with occluder implantation, in particular that of atrial fibrillation, the benefit of PFO closure compared to such modern anticoagulants remains questionable ${ }^{24}$.

This leads us to the last major objection to occluder implantation often voiced by professionals, i.e., a higher occurrence of atrial fibrillation (and other complications of occluder implantation). The risk of complication associated with the procedure itself (bleeding from the insertion point or extremely rare occluder embolization) cannot be disregarded, it is, however, lower than other mini-invasive procedures, such as percutaneous coronary intervention or the cardiac catheterization for resolution of atrial fibrillation. Development of atrial fibrillation, therefore, remains probably the most important complication (Table 1). However, it is necessary to point out that, for example, in the CLOSE study, all 11 patients with atrial fibrillation had only a single asymptomatic episode in the first month after fibrillation, which was not followed by any other episode ${ }^{20}$. Atrial fibrillation caused by the procedure thus, although it is obviously nothing to be taken lightly, may not be such an issue, especially as it seems to dwindle in association with the implementation of newer occluders and improving learning curve.

\section{DISCUSSION}

\section{Is the discussion on the interventional PE prevention closed?}

Results of studies should be viewed critically as many potential issues remain and it is not advisable to jump to conclusions. Newer studies are providing positive results the patient selection that corresponds to the study groups in the relative studies, however, remains crucial. A more detailed analysis of the results reveals that the benefits of the intervention are directly proportional to the shunt 


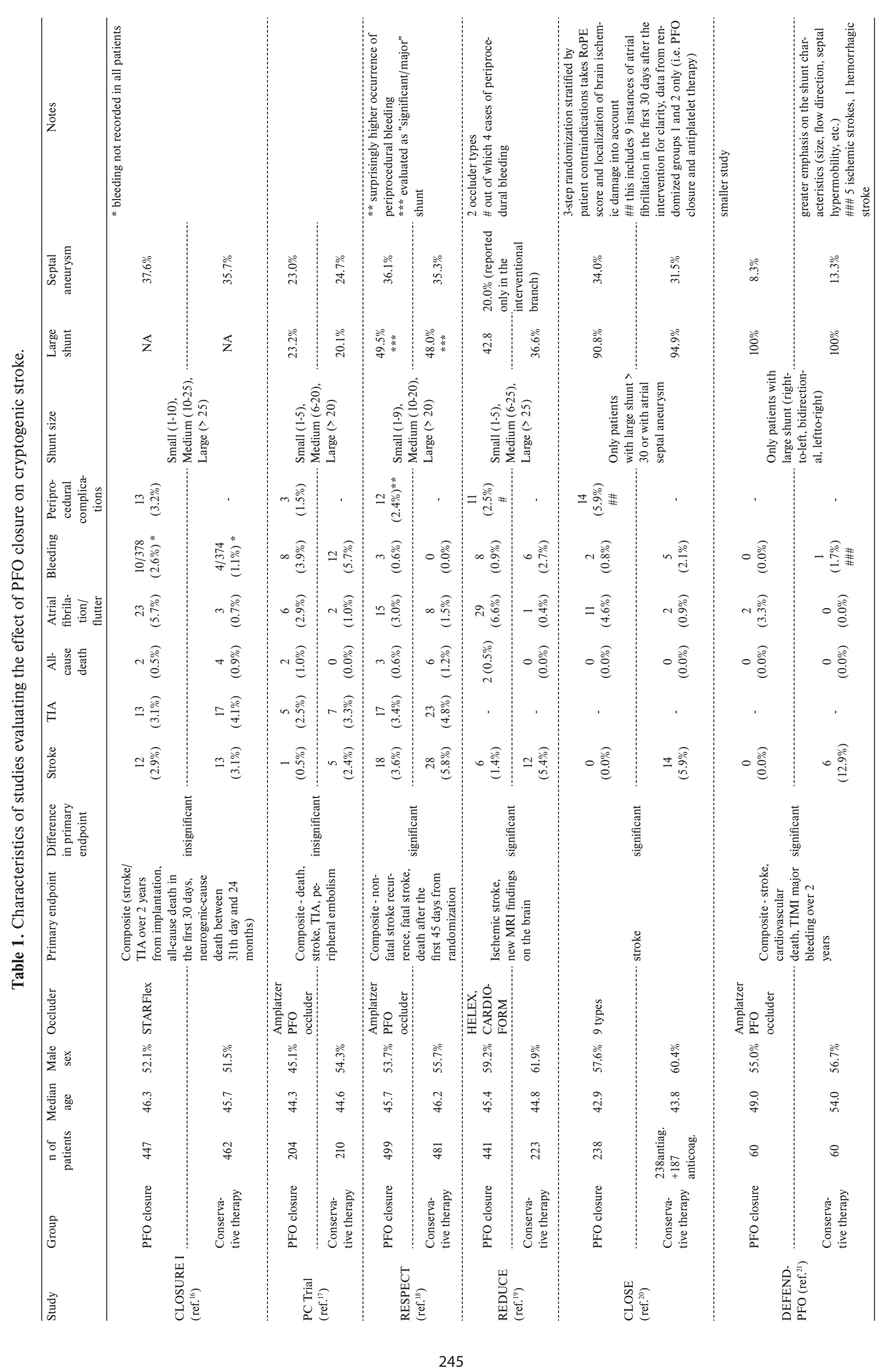


Table 2. Indication criteria for interventional PFO closure at our department.

Basic criteria for referring the patient for PFO closure

\begin{tabular}{ll}
\hline Unclear etiology of stroke//TIA & $\begin{array}{l}\text { - Rejection of atherosclerosis as a likely cause of stroke/TIA } \\
\text { (i.e., cryptogenic) }\end{array}$ \\
& (ultrasound, CT, MRI, digital subtraction angiography) \\
& Rejection of cardioembolism as a likely cause (long-term EKG Holter, ECHO) \\
& Rejection of thrombophilic condition and vasculopathy as a likely cause based on in-depth \\
& investigation \\
Echocardiography criteria (TEE) & - Proof of right-to-left shunt (spontaneous or provoked)
\end{tabular}

Additional criteria supporting decision for PFO closure

- Sufficient size of the septal rim

- Interatrial septal aneurysm

- Presence of Chiari network or persistent Eustachian valve

- Large shunt (more than 20 microbubbles)

- Pulmonary hypertension (acute, chronic)

- Mechanism/circumstances of stroke/TIA development (in particular, increased abdominal pressure)

- Lower extremity venous disease

- General condition and prognosis of the patient

- RoPE is also taken into account but not as a principal determinant ${ }^{26}$

size (i.e., benefits from the procedure were more significant in patients with bigger shunts), presence of septal aneurysm and its size. Such a detailed analysis of PFO characteristics was missing in the older studies, which may have been the reason for the insignificant difference between the conservative and interventional treatment. A greater benefit of PFO closure was confirmed in patients with bigger shunts by results of meta-analyses as well ${ }^{22}$. However, patients with such large shunts are relatively rare in everyday clinical practice, which further highlights the importance of very strict selection of patients eligible for the intervention.

Another issue (in view of the relatively low number of patients and the fact that the interventional method is still relatively young) is the follow-up period of patients with interventional solutions. As long-term data (decades) are still missing and an increased incidence of atrial fibrillation after PFO closure was reported, a question remains how many of these patients will need anticoagulation treatment at a higher age, how soon such need would arise in these patients and whether or not immediate DOAC anticoagulation could be more beneficial even in such patients.

Despite all the aforementioned controversies, it seems that the interventional PFO closure as a prevention of the secondary stroke is on the way to be generally accepted to be, in well-selected patients, beneficial. And it is exactly this issue, i.e., selection of suitable patients, which draws the most attention at this stage. It is necessary to point out that not all studies took the need for a "sufficiently strong suspicion" of a causal relationship between PFO and the ischemic stroke into account; in other words, in many patients included in the studies, the stroke might not truly meet the definitions for cryptogenic stroke. The occurrence of hypertension in patients in the studies was typically around $30-35 \%$, of dyslipidemia even as much as $40 \%$ (RESPECT) or 46\% (CLOSURE I). The representation of smokers was also relatively high in some studies, e.g. $14 \%$ in REDUCE or $>10 \%$ in RESPECT (ref. ${ }^{16-21}$ ).
Various representations of these factors might have potentially influenced the results of these studies. Nevertheless, unlike the controversies discussed above that rather downplayed the significance of the results of individual studies, the presence of these risk factors in patient groups rather suggests that the results of the studies would be even more convincing had the patients been selected with greater care.

A clearer insight into the issue of $\mathrm{PE}$ as a cause for cryptogenic stroke should be brought about by the RoPE scoring system ${ }^{26}$; nevertheless, it still needs to be confirmed by further studies before its introduction into everyday practice. The fact that it does not consider procedure-associated risks is its potential drawback for decision making whether or not to perform foramen ovale closure.

\section{Current situation}

In Europe, the differences in the opinions on the role of $\mathrm{PE}$ in the etiology and prevention of cryptogenic stroke was addressed in the position paper by the European Association of Percutaneous Cardiovascular Interventions (EAPCI), prepared in cooperation of 8 European expert associations and published in 2019 (ref. ${ }^{10}$ ).

The position paper gives clear guidelines for examinations within the scope of diagnosis of cryptogenic stroke and defines the roles of the cardiologist and neurologist in the diagnostic algorithm. Based on the results of these studies, emphasis is laid on the morphological characteristics of PFO, quality of the examination (including the patients' ability to properly perform Valsalva maneuver) and presence of other risk factors. The paper also evaluates possible complications of the procedure from the perspective of the presence of physiological variants (insufficient size of the rim of the atrial septum, hypermobile interatrial septum, insufficient total size of the septum or a long PFO tunnel). The proof of the causality between the presence of PFO and stroke is a crucial issue, again emphasizing the importance of individual decision making. The authors also focus on other nosological units 
that are possibly causally related to the PFO, such as altitude sickness, or the issue of PFO closure in divers. This document is taken into account by individual national policy-making bodies implementing its conclusions. The principal idea remains the same - the need for complex patient examination and a strict individualization when deciding about the treatment method. Table 2 summarizes parameters considered during decision making (whether or not to perform PFO closure at our department.

\section{CONCLUSION}

\section{What is the future of interventional prevention of paradoxical embolism?}

The interventional secondary prevention of PE is at present generally accepted as a good treatment option; it should be, however, used only in a carefully selected and well-defined population. The current studies no longer question whether or not the procedure can bring any benefits but rather focus on answering the question which patients will benefit most from this procedure. In the future, it is likely that the question will evolve into another question - would such a well-selected group of patients benefit from PFO closure even as a primary prevention of cryptogenic stroke? (ref. ${ }^{27}$ )

Besides, it will be necessary to properly evaluate the role and benefits of DOAC in this discussion (both in the primary and secondary prevention) and to compare the use of this modern pharmacotherapy to the interventional solution. A complex and thorough examination of patients and careful interdisciplinary selection of suitable patients remain crucial prerequisites for the successful use of this procedure.

\section{SEARCH STRATEGY AND SELECTION CRITERIA}

The research strategy was aimed at evaluating studies focused on paradoxical embolism. Scientific articles from the period 1990 to 2020 were searched using the PubMed and SCOPUS databases. Search terms included: paradoxical embolism, patent foramen ovale, closure of patent foramen ovale. Only English and Czech language papers were reviewed.

Acknowledgements: Many thanks to Dr. Jaroslav Janosek and Prof. Jan Václavík for their valuable comments and to Prof. Martin Hutyra for medical image documentation. Supported by SUG 87-85, MH CZ - DRO (FNOL, 00098892) and by SUG 87-31, MH CZ - DRO (FNOL, 00098892).

Author contributions: RN: manuscript writing, literature search; JP, MS, SH, DR, PH, MT: literature research, final approval.

Conflict of interest statement: The authors state that there are no conflicts of interest regarding the publication of this article. None declared.

\section{REFERENCES}

1. Tomek A, Bar M, Herzig R, Mikulík R, Neumann J, Šaňák D, Václavík $J$. The impact of nationwide centrally organized stroke care system on recanalization rates: Czech Republic experience. Eur Stroke J 2017;2(1):59-60.

2. Handke M, Harloff A, Bode C, Geibel A. Patent foramen ovale and cryptogenic stroke: a matter of age? Semin Thromb Hemost 2009;35(5):505-14.

3. Hudec S, Hutyra M, Precek J, Latal J, Nykl R, Spacek M, Sluka M, Sanak D, Tudos Z, Navratil K, Pavlu L, Taborsky M. Acute myocardial infarction, intraventricular thrombus and risk of systemic embolism. Biomed Pap Med Fac Univ Palacky Olomouc Czech Repub 2020;164(1):33-42.

4. Šaňák D, Hutyra $M$, Král $M$, Špaček $M$, Bártková $A$. Soumrak kryptogenní ischemické CMP - kardioembolizace je nejčastější příčina. Cesk Slov Neurol N 2018;81(3):290-97. (In Czech)

5. Homma S, Messe SR, Rundek T, Sun YP, Franke J, Davidson K, Sievert $\mathrm{H}$, Sacco RL, Di Tullio MR. Patent foramen ovale, Nat Rev Dis Primers 2016;2:15086.

6. Wessler BS, Thaler DE, Ruthazer R, Weimar C, Di Tullio MR, Elkind MS, Homma S, Lutz JS, Mas JL, Mattle HP, Meier B, Nedeltchev K, Papetti F, Di Angelantonio E, Reisman M, Serena J, Kent DM. Transesophageal echocardiography in cryptogenic stroke and patent foramen ovale: analysis of putative high-risk features from the risk of paradoxical embolism database. Circ Cardiovasc Imaging 2014;7(1):125-31.

7. Marshall AC, Lock JE. Structural and compliant anatomy of the patent foramen ovale in patients undergoing transcatheter closure. Am Heart J 2000;140:303-7.

8. Sievert H, Horvath K, Zadan E, Krumsdorf U, Fach A, Merle H, Scherer D, Schräder R, Spies H, Nowak B, Lissmann-Jensen H. Patent foramen ovale closure in patients with transient ischemie attack/stroke. J Interv Cardiol 2001;14(2):261-6.

9. Henkin S, Negrotto S, Pollak PM, Cullen MW, Fearghas M, O'Cochlain DF, Wright RS. Platypnea-Orthodeoxia Syndrome: Diagnostic Challenge and the Importance of Heightened Clinical Suspicion. Texas Heart Institute Journal 2015;42(5):498-501.

10. Pristipino C, Sievert H, D'Ascenzo F, Mas JL, Meier B, Scacciatella P, Hildick-Smith D, Gaita F, Toni D, Kyrle P, Thomson J, Derumeaux G, Onorato E, Sibbing D, Germonpré P, Berti S, Chessa M, Bedogni F, Dudek D, Hornung M, Zamorano J; European Association of Percutaneous Cardiovascular Interventions (EAPCI); European Stroke Organisation (ESO); European Heart Rhythm Association (EHRA); European Association for Cardiovascular Imaging (EACVI); Association for European Paediatric and Congenital Cardiology (AEPC); ESC Working group on GUCH; ESC Working group on Thrombosis; European Haematological Society (EHA). European position paper on the management of patients with patent foramen ovale. General approach and left circulation thromboembolism. Eurolntervention 2019;14(13):1389-1402. doi: 10.4244/ EIJ-D-18-00622.

11. Lechat $P$, Mas JL, Lascault G, Loron P, Theard M, Klimczac M, Drobinski G, Thomas D, Grosgogeat Y. Prevalence of patent foramen ovale in patients with stroke. N Engl J Med 1988;318(18):1148-52.

12. Webster MW, Chancellor AM, Smith HJ, Swift DL, Sharpe DN, Bass NM, Glasgow GL. Patent foramen ovale in young stroke patients. Lancet 1988;2(8601):11-2.

13. Mas JL, Arquizan C, Lamy C, Zuber M, Cabanes L, Derumeaux G, Coste J; Patent Foramen Ovale and Atrial Septal Aneurysm Study Group. Recurrent cerebrovascular events associated with patent foramen ovale, atrial septal aneurysm, or both. N Engl J Med 2001;345:1740-6.

14. Overell JR, Bone I, Lees KR. Interatrial septal abnormalities and stroke: a meta-analysis of case-control studies. Neurology 2000;55:1172-9.

15. Holmes DR, Cabalka A. Was your mother right - do we always need to close the door? Circulation 2002;106:1034.

16. Furlan AJ, Reisman M, Massaro J, Mauri L, Adams H, Albers GW, Felberg R, Herrmann H, Kar S, Landzberg M, Raizner A, Wechsler L. Closure or Medical Therapy for Cryptogenic Stroke with Patent Foramen Ovale. N Engl J Med 2012;366:991-99.

17. Meier B, Kalesan B, Mattle HP, Khattab AA, Hildick-Smith D, Dudek D, Andersen G, Ibrahim R, Schuler G, Walton AS, Wahl A, Windecker S, Jüni P; PC Trial Investigators. Percutaneous Closure 
of Patent Foramen Ovale in Cryptogenic Embolism. N Engl J Med 2013;368:1083-91.

18. Carroll JD, Saver JL, Thaler DE, Smalling RW, Berry S, MacDonald LA, Marks DS, Tirschwell DL. Closure of Patent Foramen Ovale versus Medical Therapy after Cryptogenic Stroke. N Engl J Med 2013;368:1092-100.

19. Søndergaard L, Kasner SE, Rhodes JF, Andersen G, Iversen HK, Nielsen-Kudsk JE, Settergren M, Sjöstrand C, Roine RO, HildickSmith D, Spence JD, Thomassen L. Patent Foramen Ovale Closure or Antiplatelet Therapy for Cryptogenic Stroke. N Engl J Med 2017;377:1033-42.

20. Mas JL, Derumeaux G, Guillon B, Massardier E, Hosseini H, Mechtouff L, Arquizan C, Béjot Y, Vuillier F, Detante O, Guidoux C, Canaple S. Patent Foramen Ovale Closure or Anticoagulation vs. Antiplatelets after Stroke. N Engl J Med 2017;377:1011-21.

21. Lee PH, Song JK, Kim JS, Heo R, Lee S, Kim DH, Song JM, Kang DH, Kwon SU, Kang DW, Lee D, Kwon HS, Yun SC, Sun BJ, Park JH, Lee JH, Jeong HS, Song HJ, Kim J, Park SJ. Cryptogenic Stroke and High-Risk Patent Foramen Ovale: The DEFENSE-PFO Trial. J Am Coll Cardiol 2018;71(20):2335-42.

22. De Rosa S, Sievert H, Sabatino J, Polimeni A, Sorrentino S, Indolfi C. Percutaneous Closure Versus Medical Treatment in Stroke Patients With Patent Foramen Ovale: A Systematic Review and Meta-analysis; Ann Intern Med 2018;168(5):343-50.
23. Dubrava J, Simkova I, Brozman M, Gdovinova Z, Kaldararova M, Krivosik M, Studencan M, Turcani P. Management of the Patent Foramen Ovale in cryptogenic ischemic stroke - Statement of the Slovak Society of Cardiology and Slovak Neurological Society. Cardiology Lett 2019;28(2-3):72-86.

24. Shatzel JJ, Daughety MM, Prasad V, DeLoughery TG. PFO closure for secondary stroke prevention: is the discussion closed? J Thromb Thrombolysis 2018;46(1):74-76.

25. Connolly SJ, Eikelboom J, Joyner C, Diener HC, Hart R, Golitsyn S, Flaker G, Avezum A, Hohnloser SH, Diaz R, Talajic M, Zhu J, Pais P, Budaj A, Parkhomenko A, Jansky P, Commerford P, Tan RS, Sim KH, Lewis BS, Van Mieghem W, Lip GY, Kim JH, Lanas-Zanetti F, GonzalezHermosillo A, Dans AL, Munawar M, O'Donnell M, Lawrence J, Lewis G, Afzal R, Yusuf S; AVERROES Steering Committee and Investigators. Apixaban in patients with atrial fibrillation. $\mathrm{N}$ Engl J Med 2011;364:806-17.

26. Kent DM, Thaler DE. The Risk of Paradoxical Embolism (RoPE) Study: developing risk models for application to ongoing randomized trials of percutaneous patent foramen ovale closure for cryptogenic stroke. Trials 2011;12:185.

27. Mojadidi MK, Mahmoud A, Patel NK, Elgendy I. Cryptogenic Stroke and Patent Foramen Ovale: Ready for Prime Time? J Am College of Cardiology 2018;72(10):1183-185. 